\title{
How Nurses Experience Their Work as a Learning Environment
}

\author{
Randi Skår
}

Received: 28 April 2009 / Accepted: 28 September 2009 /

Published online: 22 October 2009

C The Author(s) 2009. This article is published with open access at Springerlink.com

\begin{abstract}
This article explores and illuminates the meaning of nurses' experiences with their work as a learning environment. A qualitative hermeneutic approach guided the research process and the analysis and interpretation of the transcribed interview-texts of eleven graduate nurses. Three core themes emerged from these informants' descriptions of their work as a learning environment: 'participation in the work community', 'to engage in interpersonal relations' and 'accessing important knowledge resources'. The study found that, for these informants, an understanding of work as a learning environment is connected to how the nurses elect to engage in their workplaces and how the workplaces regulate their participation in activities and interpersonal relations. The nurses were aware of their responsibilities for continuous learning at work, and to confirm, create and develop their practical and professional knowledge, they obtained support from knowledgeable co-workers and chose among accessible knowledge resources in their particular workplaces. Concurrently, workplace characteristics such as the community of workers, hierarchical structures, cultural practices, and personal relations influenced learning. This understanding of the learning environment in particular workplaces shows the importance of focusing on learning processes as part of professional development in an ever-changing health care system.
\end{abstract}

This paper is part of a PhD-project which is based on institutional funding from Sogn and Fjordane University College.

R. Skår $(\bowtie)$

Faculty of Health Studies, Sogn and Fjordane University College, Box 523, 6803 Førde, Norway e-mail: randi.skar@hisf.no

R. Skår

Department of Education, Faculty of Psychology, University of Bergen, Christiesgt.13, 5015 Bergen, Norway 
Keywords Nursing practice · Learning environment · Workplace learning ·

Focus groups $\cdot$ Interview $\cdot$ Professional development

\section{Introduction}

Nurses work in ever-changing healthcare environments. Hence, learning plays a key role in their professional development, job satisfaction and the continuous improvement of patient care. Nurses have been shown to envision themselves as lifelong learners (Gerrish 2000; Jensen 2007), and to actively seek socially oriented learning activities, including exchanging, sharing, and confirming knowledge with co-workers in situations of uncertainty (Estabrooks et al. 2005), when seeking to improve their technical nursing skills (Berings et al. 2007), and when dealing with errors in their work (Bauer and Mulder 2007). Consequently, it is important to understand the factors that shape nurses' ongoing learning and as how to most effectively sustain this learning in the dynamic and demanding work environments in which they practise.

Studies of workplace learning have often noted the relationship between individual and collective learning processes in work activities (Fenwick 2008). According to Lave and Wenger (1991) and Wenger (1998), members of a work community engage in a collective process of learning. Communities of practice embedded in the relationships of the workplace create identity and give meaning to professional practice. The themes of belonging, participation, and collaboration are central to the development, function, and sustainability of a community of practice. Thus, a community of practise is 'about something', rather than simply a set of informal relationships (Alvsvåg 2008; Andrew et al. 2008). Contextual, social, and cultural factors are highly influential when individuals learn through everyday activities in the workplace (Billett 2004a, b; Eraut 2004). For example, environmental influences are foregrounded in research that has shown that nurses require learning time to provide the best patient care (Hunter et al. 2008). Previous research has also suggested that, when coupled with supportive relationships, an increased level of work-related challenges influences the confidence of nurses and their motivation to learn (Eraut et al. 2000; Wilson et al. 2006). In addition, social interactions, time, and support from peers influence the extent to which nurses utilise research (Gerrish et al. 2008; Meijers et al. 2006). Accordingly, being a member of a work community in workplaces that provide environmentally stimulating factors should influence how nurses learn.

However, in order to better understand how nurses learn in their daily work, one must also consider how they contribute to their work communities. According to Aamodt and Havnes (2008), job autonomy, co-worker support, and job commitment have a combined impact on job mastery in nursing. Within the hospital environment, autonomy and control over nursing care delivery have positive influences on nurses' interprofessional relationships (Budge et al. 2003). Nevertheless, nurses show consideration for other members of the work community as they try to avoid conflicts (Duddle and Boughton 2007) and interrupt their activities to address the desires from other team members (Hedberg and Sätterlund Larsson 2004). Hence, a social environment should not only provide opportunities to learn, but should also enable nurses to engage in complex activities and relationships in their work. This 
article, therefore, builds on the belief that learning is a process that takes place on both individual and socially shared levels. The approaches of individual nurses to active learning are central to this socially premised and situated process.

To advance this argument, the paper begins by developing a theoretical framework which underlines the importance of viewing workplaces as learning environments. Following this discussion, a qualitative study that aimed to illuminate the meaning of nurses' experiences with their work as a learning environment is presented. Findings from the study are discussed in light of previous research and the established theoretical framework. It is concluded that nurses were aware of their responsibilities regarding continuous learning at work. In addition, they experienced their work as a learning environment and were able to situate themselves as an active part of the creation of that environment.

\section{Learning and Work}

Over the past two decades, there has been much theorising about the relationship between engaging in work and learning about that work. According to Billett (2008), learning is the process in and through which workers interact with the social experience that they encounter in their workplace. Referencing socio-cultural perspectives on learning (Lave and Wenger 1991; Rogoff 1995), he states that there is no separation between thinking and acting at work, and learning (Billett 2004a, b, 2008). However, what is learned from engaging in social practices is not wholly determined by the practices themselves. Instead, because learning is a constructive process (Wertsch 1998), individuals moderate and determine what they learn from their experiences in everyday activities at work (Billett 2001a, 2008).

Viewing participation and learning as dual and reciprocal processes in which individuals exercise their agency, Billett (2001b, 2004a) highlights a need for greater insight into the processes of continuous learning throughout individuals' working lives. His theory of relational interdependence between the intentional actions of individuals and workplace practices builds on the concept that both the agency of individuals and the social environment have particular influences on worker learning. As individuals construct meaning and enact work practices, they also engage in an ongoing and active process of remaking practise as they engage in their work (Billett 2001b, 2008). Accordingly, Billett (1999, 2000, 2001a, 2004a, 2006) highlights workplaces as learning environments that give opportunities to actively engage workplace activities and provide guidance:

The kinds of values, activities, goals and guidance that are located in the workplace will likely determine how learning proceeds, what is learned and who is invited to participate and learn (Billett 2001a, page 71).

Through these opportunities to learn, individuals are invited to become a part of the development of their particular workplaces. However, whether learning is a consequence of performing these work activities or is in itself a work activity is open to question.

As opposed to formal learning in educational contexts, workplace learning is often considered informal since it is a by-product of work processes (Eraut 2004, 
2007). Informal learning processes include participation in group processes, working alongside others, tackling challenging tasks and roles, and working with clients (Eraut et al. 2000). The allocation and structuring of work are also important because they affect the extent to which the work is individual or collaborative; the opportunities for meeting, observing, and working alongside others who have more or different expertise; and the formation of relationships that might provide feedback and support (Eraut 2004, 2007). According to this view, individual learning, which is closely related to personal experiences of trust and confidence, is connected to how much an individual participates and the kinds of support that he or she receives, especially in challenging work activities.

Yet, because learning activities are important for the workplace and since engagement in work activities is intentional, describing workplaces as informal or unstructured learning environments may be imprecise (Billett 1999, 2004a). Instead, Billett (1999, 2001a, 2006) proposes a workplace curriculum as an alternative way to understand the structure and sequence of activities related to the goals and practices within a particular workplace. According to Billett (2001a, 2004a), individuals who are able to engage in increasingly complex activities and access direct and indirect guidance are probably well placed to develop vocational understanding and construct knowledge. The workplace should provide opportunities to participate in tasks that will extend one's knowledge. It should also ensure access to the direct guidance required to learn difficult or complex knowledge and to co-workers who are willing to guide and assist. It is important to point out that these qualities are shaped by workplace hierarchies, group affiliations, personal relations, and cultural practices (Billett 2001a, 2004a). This theory highlights that environments are key to individual learning activities. Individuals learn through activities and interactions during which knowledge is experienced, accessed, engaged and constructed. In this view, learning is connected to specific work communities. At the same time, however, one must consider individuals' dispositions as well as their relations to the communities in which they learn.

In a professional practice, such as nursing, it is crucial to understand how individuals develop their knowledge and capabilities throughout their working lives. According to Jensen (2007), professionals face certain challenges connected to lifelong learning because of their responsibility to maintain up-to-date professional expertise. Hence, she argues that professionals should have the ability to facilitate knowledge creation and to share knowledge. Moreover, within the nursing profession, there seems to be a connection between individual engagement, especially regarding an individual's desire to learn and the efforts made at work to develop activities that encourage learning (Jensen 2007). Accordingly, it is important to consider that both personal experiences and work activities can influence how learning takes place. Billett (2008) argues that there is a need to look beyond situated accounts of learning and development to understand learning throughout working life, as learning, identity, and one's sense of self can be influenced by one's biographical relations with social practices.

Eraut et al. (2000) found support and feedback to be critically important for learning, retention, and commitment in the first three years of employment for nurses, graduate engineers, and trainee-chartered accountants. Within nursing, the work was found to be 'over-challenging' to the newly educated. One possible reason 
for these challenges is that newly graduated nurses are unprepared for the socialisation processes in their work places, and they experience a lack of cohesion within their own profession (Kelly and Ahern 2008). Thus, a supportive environment consisting of respect and trust among the participants is crucial (Henderson et al. 2006). A Norwegian study (Wangensteen et al. 2008) found that while newly qualified nurses experience some difficulties they still describe the work environment as supportive. These nurses seemed to be confident about acknowledging their limitations connected to job mastery in specialised fields and sought guidance when they needed it. In addition, Mackintosh (2007) found that nurses become more confident in seeking support in challenging work situations after acquiring some work experience.

By focusing on how nurses experience learning in different kinds of healthcare workplace settings, this study can contribute to the current understanding of how learning throughout an individual's working life affects professional nursing practise. It provides an opportunity to analyse how these processes of knowledge creation are mediated in different ways across a range of healthcare settings. The specific research question which the study addressed was: How do nurses describe their experiences with their work as a learning environment?

\section{Investigating How Nurses Learn Through Work}

The study was guided by a qualitative hermeneutic approach inspired by Gadamer's philosophical framework. That is, throughout the study, the researcher followed the hermeneutic principles of 'openness' and 'historical consciousness' (Gadamer 1989, pp. 277-307), which state that understanding is connected to the temporality of truth such that understanding is different at different times and for different persons. In keeping oneself open to what is Other, the researcher should be aware that prejudices and preconceptions, which consist of previous experiences, meanings, and theories, will always form part of understanding. Thus, to achieve understanding between the whole and the parts in a never-ending hermeneutic circle, the interpreting process presupposes self-understanding. To recruit participants with Baccalaureate degrees in nursing and some years of work experience, the researcher contacted leaders of various health care institutions. In Norway, a three-year bachelor programme in nursing began in 2000 (Ministry of Education Research and Church Affairs 2000). The inclusion criteria therefore required that the participants graduated in 2003 or 2004 and had been working at the same workplace since graduation. Healthcare leaders searched for employees meeting these criteria, and the researcher contacted the identified nurses for voluntarily participation in the interviews. Data for this study were collected in 2006 through individual and focus group interviews. Participants included eleven female nurses working in different wards in hospitals, in nursing homes and in home nursing care in two counties in Norway (see Table 1). Following the in-depth individual interviews, focus groups expanded the inquiry by providing a different setting in which to interview the same informants. The individual interviews were completed three months before the focus groups were carried out. 
Table 1 Presentation of informants in in-depth interviews and how they were organized in focus groups

Participant description by number and workplace, used in both in-depth and focus group interviews

Focus group County 1

Focus group County 2
1. Nursing home
2. Nursing home
3. Surgery ward
4. Surgery ward
5. Rehabilitation ward ${ }^{\mathrm{a}}$
6. Community care
7. Nursing home
8. Nursing home
9. Surgery ward
10. Medical ward
11. Surgery ward

\footnotetext{
${ }^{a}$ The nurse from the rehabilitation ward was prevented from participating in the focus group interview and was interviewed individually both times.
}

\section{Dialogue in Interviews}

The individual interview guide consisted of open questions that invited the nurses to tell stories about their work in general as well as about their specific experiences with challenging work situations. The open questions were followed by questions about (i) how nurses behaved in work situations in which they lacked knowledge or experience, and (ii) how they experienced environmental influences on processes related to learning and acquiring new knowledge. The researcher attempted to clarify and expand comments made by informants by further questioning and probing (e.g., "Could you say more about that?" or "Do you mean by this that...?"). Each of the in-depth interviews lasted about 60 minutes, and each was audio-taped and transcribed verbatim by the researcher.

\section{Dialogue in Focus Group Interviews}

The analysis of the transcribed text of all in-depth interviews involved organisation of various passages into themes (Kvale and Brinkmann 2009) that constituted the topics in the focus group interview guide. The main topics were clinical leadership, decision-making and assessment, procedures and routines, communication and cooperation, and educative skills. As part of the question session in the subsequent focus groups, the interviewer presented anonymous quotations from the in-depth interviews for discussion. For example, one quotation was "The more you know, the more you know that you don't know". While some focus group questions related to previously identified topics, others aimed at expanding the previous analysis. For example, in the in-depth interviews, the nurses had emphasised the community of colleagues as an important part of their learning and development - their continual need to confer with colleagues to verify or expand their own knowledge. They also 
expressed the importance of having role models or mentors among their colleagues. Accordingly, one of the questions presented for discussion was "What is a good role model?" Overall, the questions were merely a starting point; further questioning and probing from both the researcher and all involved participants were allowed. The same interview guide was used in both focus groups.

Two assistants, one in each county and focus group, controlled the tape recording, monitored the time, and had the opportunity to ask explanatory questions when they felt it to be appropriate. Together with the interviewer, the assistants also helped to ensure that all of the nurses took part in the discussion. As teachers in nursing schools, the assistants knew some of the interviewees. However, apart from their help during the interviews, the assistants had no other roles in the project. The focus group interviews lasted for approximately 120 minutes and were transcribed verbatim by the researcher. The researcher's and the assistants' impression was that the atmosphere of the groups stimulated the expressions of critical and opposing views. The focus group discussions expanded the researcher's and the participants' understanding of the statements given during the in-depth interviews. In accordance with Krueger and Casey (2000), focus group interaction was taken into account in the analysis, with the researcher noting topics that produced consensus as well as determining the nature of any disagreements.

\section{Dialogue with the Interview Text}

Analysis moved from the dialogue with informants to dialogue with text, as the transcribed texts from both the in-depth interviews and focus group interviews formed the basis for the interpretation. To interpret the transcribed text, it was assumed that one could gain an understanding through questions asked to the transcribed text and the answers that the text produces (Gadamer 1989). To gain an understanding through this dialogue with the text, four steps proposed by Fleming et al. (2003), were followed.

In the first step the hallmarks of the dialogue with the text were the questions asked and the influence of pre-understanding on the answers that the text produced. The initial understanding from the dialogue with the participants was confirmed. The overall meaning of the transcribed text was that the experience of work as a learning environment related to how nurses handled work situations for which they were responsible. In the second step, the meaning of the experiences of participants regarding work as a learning environment was investigated. As part of this interpretation, the researcher read theory and research about workplace learning. After returning to the text, the researcher allowed themes about the text as a whole to emerge while maintaining an awareness of the influence of any new theoretical understandings on the interpretation process. The result of this step was that the meaning of work as a learning environment involves having the opportunity to confirm, obtain access to, or develop practical and professional knowledge. In the third step, the meaning of participant expressions about their experiences of work as a learning environment was investigated. The meanings of separate passages were situated in the global meaning of the text. This step produced the significant expressions: 'participation in the work community', 'to engage in interpersonal relations', and 'accessing important knowledge resources'. In the fourth step, a 
coherent interpretation was developed with respect to descriptions of nurses of their experiences of work as a learning environment. This new understanding revealed that the meaning of work as a learning environment involved nurses engaging in learning activities at work and being engaged in learning activities by their workplaces.

Throughout these four steps of interpretation, the overall approach involved openness to meaning with respect to interviewee descriptions of their experiences. This approach is an important consideration when discussing the quality of this research.

Quality of the Research Undertaken

The credibility of the research in this study depends on a clear explanation of the choices and decisions made so that reflections about the possibilities and limitations to interpretation and understanding can be easily engaged (Kvale and Brinkmann 2009; Fleming et al. 2003; Lincoln and Guba 1985). The past experiences of the researcher both as a nurse and nursing teacher influenced the interviews and interpretations. Therefore, this potential influence on the findings was considered throughout the research process (Malterud 2001). An additional goal of the study was to present a theoretical framework for interpretation (Debesay et al. 2008). Participant expressions were translated literally from Norwegian to English and are presented as anonymous quotations in this report. Informed consent was obtained from the nurses prior to the project. The nurses were advised that participation was voluntary in both interviews and that they could withdraw at any time. The transcripts were made anonymous through coding.

The possible limitations of this study are both the small sample size and the inclusion of nurses from different workplaces. However, the aim was to illuminate rather than to compare or generalise experiences.

\section{Nurse Participation, Engagement, and Access to Healthcare Knowledge}

Three themes emerged from the nurse descriptions of experiences with their workplaces as learning environments, namely "participation in the work community", "to engage in interpersonal relations", and "accessing important knowledge resources". The interpretation of nurse descriptions led to an understanding that nurse experiences of learning environments were connected to the opportunities that work provided nurses as they developed a personal engagement in learning. Representative passages that were illustrative of this shared understanding are presented below.

\section{Participation in the Work Community}

The interviewees emphasised that their work communities were structured around patients, diagnoses, tasks, and routines. The nurses found participation in their respective work communities to be an important part of gaining insight into the expected work activities and learning opportunities in their workplaces.

The nurses working in surgical and medical wards described their communities as consisting of other registered nurses, nurses with additional training, physicians, 
enrolled nurses, and other health professionals. The work community functioned as a team; sharing areas of competence and special knowledge among team members was related to the team's responsibilities towards individual patients and groups of patients. One of the nurses working in a surgery ward believed:

Even if we work independently, we are still a team, with each of us learning from one another. (9).

Another nurse working in a surgery ward described how she experienced cooperation between nurses and physicians:

We have many physicians we have to relate to. We go the round with them every day (...) Most of them are clever listening to us. If there are any problems, they listen to our opinions, because we are the one who watch the patients all the time (...) We don't actually question the treatment, but are a bit critical anyway. (4).

According to the nurse working there, the rehabilitation ward was a community characterised by its interdisciplinary nature and a holistic view of each patient, who usually stays in the ward for one to three months. The nurse described herself as a coordinator for other professionals involved in the rehabilitation process:

From the time the patient is admitted we have the responsibility for everything that happens with the patient (...) In interdisciplinary work it becomes very visible who is doing their job properly (...) The responsibility as a nurse becomes very visible. (5).

For the nurses working in nursing homes, communities consisted of few nurses; most of their co-workers were enrolled nurses and welfare workers. The nurses bear the responsibility for entire units of patients, and a physician visits the nursing home once a week or less. One of the nurses reported how she experienced her work community:

It is so different from the hospital. There you always have many people around you, physicians and...It is much lonelier here, and we don't have the opportunity to talk so much with colleagues and other nurses. We have a meeting one hour every week and of course if something special occurs. However, there are not so many professional discussions. (8).

Although the nurse in home nursing care described her work in terms of being alone with the patient, she emphasised that she worked in a community of other nurses and enrolled nurses. The community care office functioned as a meeting point. The nurse used the telephone to discuss issues with other nurses and to confirm her assessments of patient care. Each patient had a family doctor, and the nurse had the responsibility to contact the physician when needed. The nurse explained:

We are alone with the patient in his or her home, so if for instance there are serious wounds developing critically, then you have to take the responsibility for the assessment (...) So we are dependent on the patient's doctor to call him/her and talk to him/her, and they are dependent of trusting us. It is quite 
different than in hospitals and nursing homes (...) A family doctor is often difficult to get a hold of... Very often they are nowhere near a phone when you need them. (6).

These various descriptions of nurse experiences in different workplaces show the importance of including nursing roles and responsibilities in specific work communities when discussing the learning environments of nurses. Their descriptions also show how the nurses' understandings of their professional development connect to various relationships in their work communities. The next section describes how the nurses experienced these relationships and examines how nurses describe their learning in the context of having to manage workplace responsibilities.

\section{To Engage in Interpersonal Relations}

The interviewees highlighted the importance of benefiting from learning opportunities gained through relationships with their colleagues. First and foremost, the nurses emphasised that a good relationship with peers was important to feel confident in particular situations. They stated that they engaged in interpersonal relations both to prepare for performance and to obtain a confirmation of actions. Some of the interviewees mentioned having a formal mentor among more established nurses, but most of them expressed how they actively sought support in their work community. They noted that there were certain colleagues whom they trusted more or with whom they had better relations. Thus, the nurses chose their mentors and role models according to personal qualities and competence. The nurse working in a rehabilitation ward spoke about her selection:

Actually, I went looking at others discreetly and thought about whom I could ask and whom I thought was good at this and that. In a way, I chose my role models. People are good at different things. I picked up the best from each of them. (5).

The importance of the community of colleagues was discussed in the focus groups. The nurses emphasised the importance of receiving feedback and comments from colleagues both when work was done well and when mistakes were made. They discussed how a supportive culture can influence the continuous improvement of nursing practise in their workplaces and make them better at their jobs. However, the nurses expressed that they needed time to discuss and reflect upon their work with colleagues in group settings and that there should be more time set aside for professional meetings. Unfortunately, whether such arrangements actually existed seemed to depend on the workforce situation. In focus group 1, the interviewer asked why advice from the more experienced colleagues was so important. Two of the nurses working in surgery wards explained:

They have got more experience. They have tried out different procedures and know what functions well or not, or what others before them have tried out. (3).

But of course you should always be open for other possibilities than listening to those who have been there for a long time (...) Things change, and they can be obstinate about the way things have always been done. It does not have to be that way. However, you have your own persons to discuss with. (4). 
The interviewer then asked if they chose the co-workers they wanted to consult. One of the nurses working in a nursing home answered:

Maybe you ask those who are thoughtful and that you know will view things from different sides rather than those who are very obstinate and think they know what are the right things to do. (2).

In a similar discussion in focus group 2, the nurses agreed that whether they needed to confer with other nurses depended on the complexity of the situation as well as their own knowledge and experiences. The nurse working in nursing home care stated:

For instance, when it comes to procedures for healing wounds, you may feel that you can trust you know how to do it because you can try out different procedures. However, in other occasions, the consequences of what you're doing can be much more serious, and then it is important to have someone to ask among your colleagues. You can get confirmation about what to do. (6).

These statements illustrate how and when the nurses sought guidance as well as how they initiated discussions with their peers to expand their knowledge. The interviewees emphasised that they needed work experience not only to learn what to do in the context of complex patient care but also how to cooperate with co-workers. Accordingly, the nurses also had to learn to deal with disagreements in their work communities. A nurse working in a nursing home told the following story:

I think it can be difficult when I as a nurse have the professional responsibility, and when there are enrolled nurses with long experience and they have very strong opinions. It was one situation, a patient was struggling with mucus, and the enrolled nurse said that we had to help the patient absorb it, and I knew that it would just be worse if we did that. But I think it's difficult to say "No I don't want to do it". I have to stand for it and do the right things, and it's not so easy...I would feel dreadful if I did anything wrong, because I'm the one who is responsible (...) You should do the best for the patient, but you also want to satisfy others. You don't want to have dissatisfied colleagues. (8).

The nurses highlighted their responsibility for patient care while also explaining that they found it important to sustain the working climate. The experiences of nurses reported in this section underline their desire to be active in their learning. However, the work environment and social relations also affect this learning. Thus, the next section moves away from these concerns regarding how nurses both utilise and adapt to interpersonal relations to deal with how the nurses actively choose different knowledge resources accessible in their workplaces.

\section{Accessing Important Knowledge Resources}

The nurses referred to several knowledge resources that they understood to be important in their workplaces. They also explained that figuring out how to access these resources was part of the learning experience. The constant need for learning 
was emphasized by the nurses, and they had several strategies for managing these challenges. The nurse working in a medical ward shared the following:

I do not have knowledge about everything. Even if we have special areas, there is every possible kind of disease, and it is complicated and complex. It often happens that there are things I haven't come across before or know anything about, but then I can ask somebody or I can read. I constantly have to do that, and I think I will always have to do that in this job. I will never be so professionally confident that I know everything. I don't think so (...). And, of course there are things you don't feel so confident doing, but you do it anyway, and well, then you learn it. (10).

Despite their varying workplaces, all of the nurses in this study expressed a need for various kinds of specialist knowledge to meet challenges and respond to complexity in patient care. The interviewees emphasised how their workplaces provided important sources of specialist knowledge through other nurses with special training. In nursing homes, for instance, one or two nurses are given the opportunity to participate in courses to expand their knowledge in a particular field. This is done in place of training all nurses in special fields related to basic patient care. One of the nurses described the role of these nurses as contact persons:

Some contacts are specially trained for hearing, eyesight, hygiene and wound healing. Apart from that, we receive extra training in wounds and wound products, and then there are the hygiene contacts who receive their training from hygiene nurses. (2).

Nurses with formal education beyond basic qualifications (e.g. nurses with further education in hygiene, cancer, or pain treatment) were also important knowledge resources. A nurse working in a surgical ward spoke about the utility of these knowledge resources when making decisions about patient care:

We have a nurse who is specially trained in cancer. We can ask her and discuss with her what should be tried during pain treatment so that we can suggest a treatment to the physician that day, instead of delaying it for another day. (4).

Physicians were another important source of specialist knowledge. The structure of the workplace influences the ability of nurses to get to know the physicians involved in patient care. However, most of the nurses expressed their access to physician knowledge as dependent upon their ability to overcome the authority of the physicians. The home care nurse described this during a discussion in focus group 2:

It is a threshold to cross to call the physician. You just do not make a phone call for everything. It has to be pretty serious. First, you talk to a colleague or look up the relevant literature or something, and then maybe you call the physician. (6).

The medical ward nurse noted that physicians were always present on the ward. Despite this, however, she emphasised that obtaining access to their knowledge required overcoming a fear of their authority:

I decided early that I should not be afraid of them (...) I have no qualms about calling them. However, it depends on the person. Some you can ask about 
everything, and ask if they can teach you anything. After all, we cooperate often with the physicians. (10).

Some of the nurses working in nursing homes emphasised their use of Internet resources to find research and knowledge applicable to their work. They explained how their workplaces made knowledge-seeking a routine part of work. A nursing home nurse explained her need to stay current:

The things where we are independent - it is occasionally those that I need to read up on or keep myself updated on. (2).

The nurse from the rehabilitation ward expressed her systematic use of an electronic documentation system containing information on patients:

We have access to the assessments made by all the people included in the team treating the patient. Then I can get useful information, and it is not always necessary to go talk to them (i.e. the physicians or physiotherapists). (5).

The nurses working in the surgical and medical wards explained that they seldom used Internet resources due to lack of time or lack of access to these resources. Instead, they emphasised their constant need for access to updated manuals or books. They expressed that they were generally able to use these resources to find the knowledge that they needed, including, for example, information on the procedures ordinarily performed in the ward.

The findings reported in this section show how the nurses needed to access knowledge to handle various work activities. In addition, these findings show how the multiple sources of knowledge related to the characteristics of the work community and the responsibilities in the different workplaces represented in this study.

The above three sections illuminate how nurses experienced their work in terms of learning. This study particularly focused on demonstrating that nurses need further learning when entering a variety of specialised workplaces after graduation from a general nursing education programme. The reports from the nurses underline the notion that learning in these environments is related to multiple facets of workplace experience, such as how the nurses were invited to participate in work activities; in which activities they were expected to participate; how they engaged in interpersonal relations with colleagues; and how they accessed knowledge resources to confirm, create, or develop their practical and professional knowledge. Their reports elucidate the interdependence between the intentional actions of individuals and their workplace practises. This understanding of work as a learning environment with respect to nursing practice is further discussed in the next section.

\section{Nurses Work as a Learning Environment}

The nurses in this study consistently reported a need to learn in order to stay current with new developments in nursing to manage their responsibilities related to patient care. Even if much of their learning consisted of strengthening or expanding what they had already learned (Billett 2001a, 2004a; Eraut 2000), the nurses reported a 
constant need to gain new knowledge and develop their practice. As professional nurses, they claimed that it was important to develop and build expert-level knowledge rather than merely maintaining their previously acquired knowledge. According to Billett (2006) and Jensen (2007), an important factor is how opportunities at work make engagement in this learning process possible. By analysing nursing experiences in various settings, this study has captured how nurses develop learning strategies with respect to work activities, social relations, and available knowledge resources.

This study is based on the assumption that the professional learning of nurses involves belonging to, and participation and collaboration in communities of practice (Alvsvåg 2008; Andrew et al. 2008; Lave and Wenger 1991; Wenger 1998). Particular workplaces have certain work characteristics, resource allocations, and structures, which seem to influence learning (Eraut 2007). Hence, there is diversity in nurse work when it comes to the experience and background of peers and the presence of other work groups in the community. The composition of work communities is important for learning because nurses use their co-workers as mentors, role models, or knowledge resources, according to the type of activity that the work makes possible. The nurses must decide how they will engage with what is made possible by a particular social practise (Billett 2001a, 2004a).

The nurses in this study demonstrated that they actively sought knowledge and experiences to develop or construct their own practical knowledge (Billett 2001a, 2004a; Estabrooks et al. 2005). However, they also reported that they needed time and work experiences both to find their particular nursing role in their work community and to gain confidence in relationships to access the knowledge of other people in the workplace (Lave and Wenger 1991; Mackintosh 2007; Wangensteen et al. 2008). The nurses interviewed here highlighted the importance of good relationships with colleagues. As opposed to the findings of Kelly and Ahern (2008) and in accordance with Wangensteen et al. (2008), there appear to be supportive work environments within the various workplaces represented in this study. In addition, there also seems to be a unity within the nursing profession. The relationship between higher education institutions and the labour market in Norway may explain this finding (Aamodt and Havnes 2008). This sense of unity and support may also be due to the fact that nurses are often employed in workplaces in which they have completed lengthy placements during their nursing education. Thus, one might question whether employers look for both competence and an ability to adapt to one's work environment when hiring nurses. The findings of this study indicate that nurses try to avoid conflicts (Duddle and Boughton 2007) and follow the desires of co-workers (Hedberg and Sätterlund Larsson 2004). Yet the nurses interviewed here seem to adapt to various working conditions while remaining conscious of when they need to learn and how they learn from others.

The findings of this study show that nurses seek knowledge through relations in work communities when knowledge is available through co-workers. The nurse working in home nursing care had a distant relationship with the physicians in the facility. She knew that they were difficult to reach and therefore had to assess situations using her own knowledge as well as engaging in discussion with other nurses when appropriate. Nursing home nurses described a lack of accessible peers and physicians which could be a reason why they use Internet resources to access 
research and other information needed for their work (Gerrish et al. 2008; Meijers et al. 2006). Nurses in hospitals with access to rich human and textual knowledge resources should have the best conditions for the expansion of their knowledge. The findings of this study indicate that a power imbalance between nurses and physicians could hinder this exchange of knowledge. However, the nurses reported that their authority with respect to holistic patient care and their capacity to protect patient needs positively influenced their cooperation with physicians and other professionals (Budge et al. 2003; Skår 2009).

The work situation determined the learning activity chosen by the nurses (Berings et al. 2007) as well as whether they needed to confirm their own knowledge or access new knowledge. They consulted other professionals whom they knew had the appropriate experience or special knowledge to solve a particular problem or task (Bauer and Mulder 2007; Estabrooks et al. 2005). However, access to this special knowledge depended on the activities in which the nurses engaged and how their particular workplaces were structured. This is illustrated by the nursing home nurse's use of contact persons with knowledge connected to basic fields. In surgical and medical wards, nurses required knowledge from other specially trained nurses to participate in decisions about patient treatment. Another illustration comes from the rehabilitation ward in which work was interdisciplinary; there, the documentation system helped one nurse obtain the necessary information from all professionals involved in a patient's care. These reports stress that the complexity of work affected learning in nursing practise (Eraut 2007; Hunter et al. 2008) and motivated individual learning (Wilson et al. 2006). In addition, this study shows how engagement in work activities led to the discovery of the need for further learning (Billett 2004b, 2008). This means that engaging in increasingly complex activities enabled the nurses to develop their professional understandings and construct their own knowledge.

These reports from the nurses participating in this study demonstrate the importance of working alongside others and obtaining support to learn from work processes (Eraut et al. 2000; Eraut 2004, 2007). Moreover, the nurses demonstrated an intention to learn by seeking both close and indirect guidance in their work (Billett 1999, 2000).

The nurses also found it informative to follow and observe more experienced co-workers or peers who were "good at something", as one of the nurses stated. In addition, the nurses wished to discuss and reflect with peers, thus sharing their strong points as well as their limitations (Bauer and Mulder 2007). They seemed to be aware that guidance was a learning activity that helped them gain insight into what types of knowledge were available and required in their particular workplaces (Billett 2001a). The nurses claimed that they selected support from various individuals to achieve the best learning experiences.

\section{Nursing, Learning and Work}

In accordance with previous research, this study concurs with the finding that interpersonal relations and processes have a major influence on learning and job mastery in nursing practice (Bauer and Mulder 2007; Berings et al. 2007; Estabrooks 
et al. 2005; Eraut 2007; Aamodt and Havnes 2008). In addition, this study underscores the personal role in collective learning processes (Billett 2001b, 2008) and the importance of nurses' engagement in learning as part of their professional work (Jensen 2007). That is, ultimately, it is the active actions of nurses which shape the quality of healthcare workplaces as learning environments.

This study proposes that to understand work as a learning environment, it is important to take into consideration the fact that individuals elect how they engage in their workplaces, and that workplaces intentionally regulate individuals' participation (Billett 2001a, 2004a). The findings indicate that nurses experience their work as a learning environment when they can define themselves as an active part in the creation of that environment. Nurses seek guidance from other people in their workplace to confirm, construct and develop their practical and professional knowledge. However, the allocation and structuring of the work has an influence on whom 'the others' are, and the hierarchical structures, cultural practices, and personal relations in the workplace influence the accessibility of knowledge and experiences. Most of the nurses in this study stated that they would like more organised learning in their workplaces, with opportunities to reflect upon their work and discuss professional issues. They expressed a desire to know whether their engagements in learning activities are in accordance with the goals and directions of their work. These reports illuminate the need for workplace curricula in nursing practices, which provide opportunities to participate in tasks that will extend knowledge as well as the guiding resources connected to various professionals in the particular work community. For instance, the nurses in this study emphasised that they included physicians in their community of co-workers, and saw them as having an important role in their learning environment. The study highlights individual learning engagement among the represented nurses. Nevertheless, it could be asked whether the workplaces should pay more attention to learning as a work activity. Workplace learning is an important part of professional development when learning as a process changes both the learner and the environment. The field of nursing is various and ever-changing. Thus, learning processes in particular workplaces should be emphasised in further research on professional nursing practice.

Acknowledgements I would like to acknowledge the contribution of the nurses involved in this study and would like to thank them for allowing me to share their unique experiences. I would also like to thank my supervisors, Associate Professor Herdis Alvsvåg and Professor Berit Karseth, for their support and encouragement throughout the writing of this article.

Open Access This article is distributed under the terms of the Creative Commons Attribution Noncommercial License which permits any noncommercial use, distribution, and reproduction in any medium, provided the original author(s) and source are credited.

\section{References}

Aamodt, P. O., \& Havnes, A. (2008). Factors affecting professional job mastery: quality of study or work experience? Quality in Higher Education, 14, 233-248.

Alvsvåg, H. (2008). The nurse's learning through the patient's encounter with death. Klinisk Sygepleje, 22, $5-14$.

Andrew, N., Tolson, D., \& Ferguson, D. (2008). Building on Wenger: communities of practice in nursing. Nurse Education Today, 28, 246-252. 
Bauer, J., \& Mulder, R. H. (2007). Modelling learning from errors in daily work. Learning in Health \& Social Care, 6, 121-133.

Berings, M. G. M. C., Poell, R. F., Simons, P. R.-J., \& Van Veldhoven, M. J. P. M. (2007). The development and validation of the on-the-job learning styles questionnaire for the nursing profession. Journal of Advanced Nursing, 58, 480-492.

Billett, S. (1999). Guided learning at work. In D. Boud \& J. Garrick (Eds.), Understanding learning at work (pp. 151-164). London and New York: Routledge.

Billett, S. (2000). Guided learning at work. Journal of Workplace Learning, 12, 272-283.

Billett, S. (2001a). Co-participation: affordance and engagement at work. In T. Fenwick (Ed.), Sociocultural perspectives on learning through work (pp. 63-72). San Francisco: Jossey Bass/Wiley.

Billett, S. (2001b). Learning throughout working life: interdependencies at work. Studies in Continuing Education, 23, 19-35.

Billett, S. (2004a). Learning through work: workplace participatory practices. In H. Rainbird, A. Fuller \& A. Munro (Eds.), Workplace learning in context (pp. 109-125). London and New York: Routledge.

Billett, S. (2004b). Workplace participatory practices: conceptualising workplaces as learning environments. Journal of Workplace Learning, 16, 312-324.

Billett, S. (2006). Constituting the workplace curriculum. Journal of Curriculum Studies, 38, 31-48.

Billett, S. (2008). Learning throughout working life: a relational interdependence between personal and social agency. British Journal of Educational Studies, 56, 39-58.

Budge, C., Carryer, J., \& Wood, S. (2003). Health correlates of autonomy, control and professional relationships in the nursing work environment. Journal of Advanced Nursing, 42, 260-268.

Debesay, J., Nåden, D., \& Slettebø, Å. (2008). How do we close the hermeneutic circle? A Gadamerian approach to justification in interpretation in qualitative studies. Nursing Inquiry, 15, 57-66.

Duddle, M., \& Boughton, M. (2007). Intraprofessional relations in nursing. Journal of Advanced Nursing, 59, 29-37.

Eraut, M. (2000). Non-formal learning and tacit knowledge in professional work. British Journal of Educational Psychology, 70, 113-136.

Eraut, M. (2004). Informal learning in the workplace. Studies in Continuing Education, 26, $247-273$.

Eraut, M. (2007). Learning from other people in the workplace. Oxford Review of Education, 33, 403-422.

Eraut, M., Alderton, J., Cole, G., \& Senker, P. (2000). Development of knowledge and skills at work. In F. Coffield (Ed.), Differing visions of a learning society (Vol. I, pp. 231-262). Bristol: Policy.

Estabrooks, C. A., Rutakumwa, W., O’Leary, K. A., Profetto-McGrath, J., Milner, M., Levers, M. J., et al. (2005). Sources of practice knowledge among nurses. Qualitative Health Research, 15, 460-476.

Fenwick, T. (2008). Understanding relations of individual-collective learning in work: a review of research. Management Learning, 39, 227-243.

Fleming, V., Gaidys, U., \& Robb, Y. (2003). Hermeneutic research in nursing: developing a Gadamerianbased research method. Nursing Inquiry, 10, 113-120.

Gadamer, H.-G. (1989). Truth and method. London: Sheed \& Ward.

Gerrish, K. (2000). Still fumbling along? A comparative study of the newly qualified nurse's perception of the transition from student to qualified nurse. Journal of Advanced Nursing, 32, 473-480.

Gerrish, K., Ashworth, P., Lacey, A., \& Bailey, J. (2008). Developing evidence-based practice: experiences of senior and junior clinical nurses. Journal of Advanced Nursing, 62, 62-73.

Hedberg, B., \& Sätterlund Larsson, U. (2004). Environmental elements affecting the decision-making process in nursing practice. Journal of Clinical Nursing, 13, 316-324.

Henderson, A., Winch, S., \& Heel, A. (2006). Partner, learn, progress: a conceptual model of continuous clinical education. Nurse Education Today, 26, 104-109.

Hunter, C. L., Spence, K., McKenna, K., \& Iedema, R. (2008). Learning how we learn: an ethnographic study in a neonatal intensive care unit. Journal of Advanced Nursing, 62, 657-664.

Jensen, K. (2007). The desire to learn: an analysis of knowledge-seeking practices among professionals. Oxford Review of Education, 33, 489-502.

Kelly, J., \& Ahern, K. (2008). Preparing nurses for practice: a phenomenological study of the new graduate in Australia. Journal of Clinical Nursing, 18, 910-918.

Krueger, R. A., \& Casey, M. A. (2000). Focus groups: a practical guide for applied research. Calif.: Sage, Thousand Oaks.

Kvale, S., \& Brinkmann, S. (2009). Interviews: learning the craft of qualitative research interviewing. Los Angeles: Sage.

Lave, J., \& Wenger, E. (1991). Situated learning: legitimate peripheral participation. Cambridge: Cambridge University Press.

Lincoln, Y. S., \& Guba, E. G. (1985). Naturalistic inquiry. Beverly Hills, Calif.: Sage. 
Mackintosh, C. (2007). Protecting the self: A descriptive qualitative exploration of how registered nurses cope with working in surgical areas. International Journal of Nursing Studies, 44, 982-990.

Malterud, K. (2001). Qualitative research: standards, challenges, and guidelines. Lancet, 358, 483-488.

Meijers, J. M. M., Janssen, M. A. P., Cummings, G. G., Wallin, L., Estabrooks, C. A., \& Halfens, R. Y. G. (2006). Assessing the relationships between contextual factors and research utilization in nursing: systematic literature review. Journal of Advanced Nursing, 55, 622-635.

Ministry of Education Research and Church Affairs. (2000) General plan and regulations for 3-year training programme in nursing. http://www.safh.no/english/legislation/regulations/sykepl-rammeplanengelsk-apr03.pdf.

Rogoff, B. (1995). Observing sociocultural activities on three planes: participatory appropriation, guided appropriation and apprenticeship. In J. V. Wertsch, P. Del Rio \& A. Alverez (Eds.), Sociocultural studies of the mind (pp. 139-164). New York: Cambridge University Press.

Skår, R. (2009). The meaning of autonomy in nursing practice. Journal of Clinical Nursing [article online in advance of print]. Retrieved September 9, 2009, from http://www3.interscience.wiley.com/journal/ 122457283/abstract.

Wangensteen, S., Johansson, I. S., \& Nordström, G. (2008). The first year as a graduate nurse-an experience of growth and development. Journal of Clinical Nursing, 17, 1877-1885.

Wenger, E. (1998). Communities of practice: learning, meaning, and identity. Cambridge: Cambridge University Press.

Wertsch, J. V. (1998). Mind as action. New York: Oxford University Press.

Wilson, V., McCormack, B., \& Ives, G. (2006). Re-generating the 'self' in learning: developing a culture of supportive learning in practice. Learning in Health \& Social Care, 5, 90-105.

Randi Skår work as an assistant professor in Faculty of Health Studies, Sogn and Fjordane University College in Norway. She is also a PhD-student in Faculty of Psychology, University of Bergen. The exploratory focus in her $\mathrm{PhD}$-project (2005-2009) is the education and work qualifications required by the nursing profession. 